\author{
G. Pambianchi, M. Materazzi \& F. Pallotta
}

\title{
The geomorphological landscape of the archaeological park of Selinunte
}

\begin{abstract}
Pambianchi, G., Materazzi, M. \& Pallotta, F.: The geomorphological landscape of the archaeological park of Selinunte. - Bocc. 28: 27-28. 2019. - ISSN: 1120-4060 printed, 2280-3882 online.
\end{abstract}

Key words: landscape evolution, photointerpretation, drones, sedimentology.

The research, still in progress, is aimed at the reconstruction of the landscape evolution (since early Holocene) in the area of the Archaeological Park of Selinunte. Through field surveys and indirect investigations, it is bringing a fundamental contribution to the knowledge of the natural and anthropic events that characterized the development of the Selinunte's civilization.

The research includes:

a) Geomorphological investigations and landscape evolution during historical times.

The use of Li.DAR images, aerial photos and field surveys allowed to reconstruct the ancient coast morphology, characterized by wide gulfs at the mouth of the major rivers and to hypothesize the existence of river channels favorable to navigability with small boats for long sectors inward.

b) Climate change and relationships with historical events.

The geomorphological analyses and the reconstruction of the paleoclimatic context allowed to hypothesize an arid-cold climatic phase in the period of maximum development of the Selinunte's civilization (between 6th and 4th centuries B.C.), which caused, as proven by historical sources, the formation of swampy and unhealthy areas with consequent spread of diseases and pestilences. In this regard, the same studies have also provided a hypothesis on type and location of the famous hydraulic work and reclamation work carried out by Empedocle in 444 BC. (described by Diogene Laerzio in the III century BC).

c) Geological and sedimentological investigations on building materials.

During the study, numerous rock samples were taken from the main mining areas and subjected to mineralogical-petrographic analyses. The results confirm age and compo- 
sition of the materials constituting the geological bedrock and are allowing to correlate the different buildings with the areas of origin.

d) Hydrogeological investigations and studies on water resources availability.

The information gathered on the current water resource availability and hypotheses on the water demand in historical times, allowed to formulate some hypotheses on location, type and consistency of the springs in the period of maximum development of the Selinunte's civilization.

e) Indirect investigations: use of Unmanned Aerial Vehicle (UAV - drones) and geophysical prospecting

The use of drones equipped with photocameras and thermal cameras made it possible to highlight, on the whole area of the archaeological park the presence, on the ground or in the immediate subsoil, of numerous anomalies attributed to anthropic activities and presence of manufacts. These anomalies may be confirmed in the future and investigated through essays or excavation campaigns.

Address of the authors:

Gilberto Pambianchi, Marco Materazzi \& Fabio Pallotta,

School of Science and Technologies (Geology Division), University of Camerino, Italy. E-mail: gilberto.pambianchi@unicam.it 